\title{
Public health nutrition workforce composition, core functions, competencies and capacity: perspectives of advanced-level practitioners in Australia
}

\author{
Roger Hughes* \\ Nutrition Unit, School of Health Science, Griffith University, Gold Coast, Queensland 4217, Australia
}

Submitted 23 October 2002: Accepted 14 February 2003

\begin{abstract}
Objectives: To investigate the attitudes, experiences and beliefs of advanced-level public health nutritionists with respect to public health nutrition workforce composition, core functions, competency requirements and existing workforce capacity.

Design: Qualitative study using structured interviews.

Setting: Australia.

Subjects: Forty-one advanced-level public health nutritionists employed in academic and senior technocratic positions in state health systems.

Results: Advanced-level public health nutritionists recognise the diversity of the public health nutrition workforce but clearly identify the need for a specialist public health nutrition workforce tier to provide workforce leadership. Nominated core functions for public health nutrition reflect broader public health core functions but, in the context of nutrition, specific problem resolution. Opinions about competency needs were similar to many of the cross-cutting competencies identified in the public health field but with specific application to nutrition problems. Competency in the scientific underpinning of nutrition was considered particularly important and delineated this public health nutrition workforce from the broader public health workforce. Public health nutrition was identified as a specialisation within public health and dietetics. Workforce capacity assessments by this group indicate a need for workforce development.

Conclusions: Qualitative data from a large proportion of the Australian public health nutrition leadership group have identified core functions, competencies and workforce development priorities that can be a basis for further systematic research and workforce strategy development.
\end{abstract}

Workforce development is an important public health nutrition strategy that builds societal capacity for organised efforts to address nutrition-related problems in communities. Despite recognition of the importance of efforts to build workforce capacity through training and other measures internationally ${ }^{1}$, there is limited literature that can be used to inform strategic workforce development in the public health nutrition field. This emphasises the importance of research to provide an intelligence base for strategic workforce development.

Despite considerable professional debate about definitions, role delineation and competencies for public health nutrition in Australia ${ }^{2-10}$, there is still a lack of intelligence about the public health nutrition workforce. Information about the composition, size, practices, demographics, educational attributes and training needs required for efficient and strategic workforce development is limited. These epistemological barriers to workforce development are consistent with those identified for the broader public health workforce ${ }^{11,12}$. The launch of the 10-year national agenda for action on public health nutrition in Australia in 2001 (Eat Well Australia) ${ }^{13}$ has provided a mandate for accelerated public health nutrition workforce development under its capacity building priority area. In the absence of workforce intelligence, efforts to build workforce capacity are at risk of being misguided or inefficient.

Considerations about the composition of the public health nutrition workforce and approaches to interdisciplinary collaboration and effort have been identified as critical features of effective training, workforce development and intervention ${ }^{14}$.

There is a developing consensus, at least in Australia, that the public health workforce can be categorised into a number of workforce tiers with different development needs, roles and functions, but all part of the collective 
capacity of the workforce $e^{10,15}$. Most of the available literature profiling the public health nutrition workforce has been discipline-specific ${ }^{7,16-18}$.

Various attempts have been made internationally to codify the core functions of public health ${ }^{19,20}$ and there is a developing literature about public health nutrition-related competencies ${ }^{14,21-25}$. Many of the competencies identified in this literature are similar, with considerable overlap across fields. There has been no known specific investigation of the competency needs for public health nutrition practice in Australia.

A combination of factors such as workforce composition, level of collaboration, competencies, practice methods, information access, resource allocation and organisational issues are likely to impact on the capacity of the workforce to address population nutrition problems effectively. This makes research that investigates the influence of these factors on workforce capacity an important component of systematic and strategic workforce development.

This study aimed to investigate the attitudes, experiences and beliefs of advanced-level public health nutritionists in Australian health bureaucracies and academic institutions with respect to workforce composition, core functions, competencies and workforce capacity. This exploration provides a basis for broader workforce intelligence gathering and strategy development, consistent with a systems approach to public health workforce development ${ }^{26}$.

\section{Methodology}

\section{Design}

A qualitative study design using semi-structured interviews amongst information-rich cases was employed.

\section{Subject recruitment}

Advanced-level public health nutritionist is a title adapted from workforce studies in the USA ${ }^{25}$. Advanced-level public health nutritionists were identified as senior government-level public health nutrition practitioners (SGPHNs) and academic public health nutritionists (APHNs) from Australian universities with programmes in professional nutrition practice (nutrition and dietetics, public health nutrition and community nutrition). Invitations to participate in the study were directed purposively through known faculty and professional networks and snowball sampling techniques.

\section{Data collection}

A series of structured interviews was conducted using a list of open-ended questions (Table 1) used as a basis for discussion. These questions were forwarded to interviewees prior to the interview to enable considered responses. Persistence with interviews after new themes appeared to be exhausted (interview redundancy) was applied to ensure all opinions were canvassed and identified within the limits of this method. Interviews were audio-taped and transcribed verbatim.

\begin{abstract}
Analysis
Responses from transcripts were sorted thematically into response categories using a content analysis approach. Key themes were then considered in the context of the inquiry logic depicted in Table 1. Narrative script has been included in the presentation of results to illustrate and typify the types of responses and themes reported. The discourse analysis has placed emphasis on analysing the content or structure of the narrative in its original or intact form, and provides conflicting points of view when disagreement existed. Where considered useful, enumeration of key response themes was conducted to illustrate the consistency or variation in response themes.
\end{abstract}

\section{Results}

\section{Participant characteristics}

A total of 41 advanced-level public health nutritionists (26 APHNs and 15 SGPHNs) were interviewed,

Table 1 Interview questions guide and inquiry logic

\begin{tabular}{|c|c|}
\hline Question & Inquiry logic \\
\hline $\begin{array}{l}\text { How would you describe the composition } \\
\text { of the Australian public health nutrition workforce? }\end{array}$ & $\begin{array}{l}\text { Who practitioners include when considering the } \\
\text { public health nutrition workforce }\end{array}$ \\
\hline $\begin{array}{l}\text { What do you consider are the core functions } \\
\text { of the public health nutrition workforce? }\end{array}$ & $\begin{array}{l}\text { What practitioners consider to be defining } \\
\text { functions of the public health nutrition workforce }\end{array}$ \\
\hline $\begin{array}{l}\text { What competencies (skills, knowledge and attitudes) } \\
\text { would you identify as being necessary for } \\
\text { effective public health nutrition practice? }\end{array}$ & $\begin{array}{l}\text { What practitioners consider to be defining } \\
\text { competencies of the public health nutrition } \\
\text { workforce }\end{array}$ \\
\hline $\begin{array}{l}\text { Do you think competencies for public health nutrition } \\
\text { are different to those for generic public health? }\end{array}$ & $\begin{array}{l}\text { Are competencies for public health nutrition } \\
\text { similar to those for public health } \\
\text { and if not how do they vary? }\end{array}$ \\
\hline $\begin{array}{l}\text { How would you rate your state workforce's existing } \\
\text { capacity to implement the EWA strategy? }\end{array}$ & $\begin{array}{l}\text { Opinions about existing workforce capacity reflects } \\
\text { workforce development needs }\end{array}$ \\
\hline
\end{tabular}

EWA - Eat Well Australia: National Public Health Nutrition Strategy. 
representing all Australian states and its two territories. Staff representing all but two of the 11 universities with professional nutrition and dietetic, community and public health nutrition programmes were recruited and participated in this interview process.

This sample was highly qualified in nutrition and/or dietetics, with most (33/41) having more than two university qualifications and over half (23/41) having completed or currently participating in doctorate studies. Almost one-quarter (11/41) had completed a combination of dietetic training followed by a Master of Public Health. The sample was dominated $(37 / 41)$ by practitioners with dietetic qualifications as their entry-level professional qualification. This sample was similarly highly experienced, with most (34/41) having more than 10 years' experience in community and public health nutrition practice (Table 2).

\section{Interview redundancy}

There was generally a high level of within- and betweengroup (APHN and SGPHN) consistency in responses obtained, with a quick reduction in new response themes becoming apparent after eight to 10 interviews in both groups.

\section{Workforce composition}

A range of health professionals were identified as constituents of the public health nutrition workforce. It was apparent that most interviewees recognised the multidisciplinary nature of the public health nutrition workforce, and that a broad and inclusive view of the workforce composition was evident. Having a population and prevention focus and being employed with public funds were suggested as defining criteria:

'It is a disparate workforce with no real professional structure.

'I could include anyone that does nutrition as part of their work.'

'All those that identify themselves that way.'

Specialist nutritionists were the most commonly identified workforce category. Recognition of the importance of the specialist tier of the workforce with experience and higher qualifications in public health was obvious. This was qualified by comments about the need for a leadership group in the workforce with high-level competencies to facilitate action. Health promoters, aboriginal health workers, academics and nurses were also commonly considered as important components of the workforce:

In some areas... such as rural areas... it's the nonnutritionists who are doing most of the nutrition program implementation... and in many instances they are the best ones to be doing this.'

'The workforce is potentially very broad ... but it is a fallacy to expect that non-specialists would embrace nutrition as their priority.'

\section{Core functions}

Interviewees nominated a large range of functions $(>20)$ considered to be core functions for public health nutrition practice. There was general agreement that the core functions for public health nutrition were similar to those for public health but with a specific focus on nutrition issues and methods (Table 3):

'The core functions forpublic bealth nutrition are the same as for public health but in a nutrition context'.

Intervention management (needs assessment, planning, strategy design, implementation and evaluation) was the most common core function theme. One interviewee's response illustrated the complexities of public health nutrition issues and the need for broad public health approaches to problem resolution:

'We had a situation of iron deficiency, lead in the dust, poor nutrition, hookworm, use of ceramics with lead in the glaze... so there were a range of confounders... what we did was paid landlords to paint their houses, got kids to wear shoes, introduced iron-fortified cereals, removed the dirt... we never knew which of these eradicated the problem but after two years we saw lead levels drop and iron deficiency decline ... it was a multi-prong approach ... a public bealth approach ... not just a nutrition approach.'

Table 2 Interviewee sample characteristics summary

\begin{tabular}{lc}
\hline & APHNs $(n=26)$ \\
\hline Number of academic qualifications ${ }^{\star}$ (range) & $3.4(2-5)$ \\
Mean years of experience in community and public health nutrition practice $(n=15)$ & 16 \\
Number with 10 or more years' experience in community and public health nutrition practice & $3.2(2-4)$ \\
Number with doctorate-level qualification & 13.4 \\
Number currently doing doctorate-level qualification & 14 \\
Number with Master of Public Health & 20 \\
Number currently doing Master of Public Health & 4 \\
\end{tabular}

APHN - academic public health nutritionist; SGPHN - senior government-level public health nutrition practitioner.

*University-level qualifications including undergraduate degree and postgraduate diplomas, Master's and doctorate degrees. 
Table 3 Summary of most commonly identified core functions of the public health nutrition workforce compared with core functions for public health

\begin{tabular}{|c|c|c|}
\hline & $\begin{array}{l}\text { Consistent with core functions } \\
\text { for public health }\end{array}$ & $\begin{array}{l}\text { Total nominations } \\
\text { from } 41 \text { interviewees }\end{array}$ \\
\hline Programme management ${ }^{*}$ & $A+U S$ & 16 \\
\hline Research, including intervention research & US & 16 \\
\hline Evaluation* & US & 14 \\
\hline Advocacy & & 12 \\
\hline Needs assessment ${ }^{*}$ & $A+U S$ & 12 \\
\hline Nutrition monitoring and surveillance & US & 11 \\
\hline Scientific and lay communication & $A+U S$ & 9 \\
\hline Policy development & $A+U S$ & 9 \\
\hline Workforce development & $A+U S$ & 7 \\
\hline Intersectoral collaboration & & 6 \\
\hline Community development & A & 6 \\
\hline
\end{tabular}

Only functions mentioned by $>5$ interviewees are listed.

A - consistent with core functions for public health identified in Australia ${ }^{19}$; US - consistent with core functions for public health identified in the USA ${ }^{20}$. ${ }^{*}$ Components of intervention management.

\section{Competency expectations}

There were over 40 different public health nutrition competency units identified by interviewees that contribute to workforce effectiveness. These were broad in scope, with many generic to public health practice. A number of respondents argued that competencies should relate directly to performing the core functions of public health nutrition.

The most common competency themes (Table 4) included communication skills, analytical skills (including data analysis, literature critique and epidemiology), nutrition knowledge, research and evaluation skills, knowledge of public health approaches and frameworks, and advocacy and policy process skills.

Government-employed public health nutritionists tended to be more consistent than academics in their nominations of competencies related to nutrition knowledge, advocacy and policy processes. Academics tended to favour research competencies more consistently. Most interviewees commented that the competencies for public health nutrition were post-basic, applied to professional practice and depended on the level and context of employment:

Table 4 Summary of most commonly identified competency expectations of the public health nutrition workforce

\begin{tabular}{lc}
\hline & $\begin{array}{c}\text { Total nominations } \\
\text { from 41 interviewees }\end{array}$ \\
\hline Communication skills & 15 \\
Analytical skills & 15 \\
Nutrition knowledge & 15 \\
Research and evaluation & 14 \\
Public health/health promotion methods & 13 \\
Advocacy and policy processes & 13 \\
Epidemiology & 11 \\
Grantsmanship and writing & 9 \\
Project management & 8 \\
Management of human & 7 \\
and financial resources & \\
\hline
\end{tabular}

Only functions mentioned by $>5$ interviewees are listed.
'Although the jobs differ I'm not sure the competencies do ... maybe the level of application or the emphasis.'

I'm not sure that it is any easier working at a local level than a national level ... often the structures at a national level are much more defined which makes it easier.'

One respondent's comment raised a question as to whether competencies should be considered as a minimum standard for an individual practitioner or as a mix of competencies required by a work group:

'The extent and breadth of competencies required for effective public bealth nutrition make it difficult for individuals to

have competencies in all areas ... Working in collaboration with others is a critical competency in itself.'

The majority of interviewees tended to agree with the notion that public health nutrition competencies are consistent with most generic public health competencies, but with a consistent qualifier that the public health nutrition workforce requires additional competency units in nutritional sciences:

'Public health nutrition issues are in shades of grey rather than being black and white like other public bealth issues. This makes for practice that requires a strong background and understanding of the relationships between behaviour, food supply, consumption and its effect on bealth.'

I think you need an overlay of nutrition and public bealth competencies to be a public health nutritionist.'

'Nutrition is an area in public bealth ... And it is often more complex with a lot of confounding and needs more science than many other public health issues.'

There was a common theme expressed that public health nutrition is a specialisation within public health and that a tendency towards generalising the workforce was counterproductive to developing workforce effectiveness: 
'There is a disturbing tendency to want to generalise competencies ... specialisation is important in food and nutrition because it is so complex a problem ...'

'Most public health practitioners have a specialty. . so relying on other public bealth staff without nutrition skills is inefficient.... the dearth of nutrition content area expertise means we need nutrition specialists.

'I think we have a lot of good public health workers trying to do nutrition work, but not doing it very well because they lack the understanding and insight that nutritionists have.'

Comparisons between epidemiology and nutrition epidemiology were used to analogise the differences between generalist and specialist approaches and emphasise the importance of competencies in nutritional sciences:

'I think it is difficult for a public health graduate without nutrition training to be effective ... its like an epidemiologist without nutrition background doing nutrition studies that produce odds ratios based on dietary exposures that are ridiculous... understanding of the nutrition science is crucial.'

\section{Effectiveness of the public bealtb nutrition workforce}

When asked to rate the effectiveness of the public health nutrition workforce in addressing identified public health nutrition priorities, there was considerable disagreement in response themes; most were qualified with supporting comments:

'Oh, about 5 out of 10 ... we have been OK at raising community awareness but that is limited in terms of bringing about change.'

I don't think we have tried and failed... I think we just haven't tried... because we have yet to apply the resources and will at a societal or government level to address nutrition problems.'

Those who reported that the workforce had been effective identified infrastructure growth, dietary guidance tools and some outcomes as evidence of effectiveness:

'Effectiveness is reflected in the growth in infrastructure in our state... managers are seeing the value in our work, and this is leading to workforce growth.'

'You know I think that it would be interesting to see what would have happened if we hadn't had a public health nutrition workforce in Australia at all... The RDIs have been built up, the food standards code exists, the nutrient data bases in Australia... All those tools wouldn't exist if there hadn't been a public health nutrition workforce... we've had two national nutrition surveys, we have got some research that happened around the universities in terms of the links between the diet and disease... this has all been fundamental.'
Difficulties with measuring workforce effectiveness were commonly identified, and many respondents commented that a lack of evidence did not equate with a lack of effectiveness:

'We need to challenge the evidence-based dogma ... collecting evidence from public bealth nutrition interventions is difficult particularly in the short term and when investments have been limited.'

'You can't feasibly assess the value of much of public bealth nutrition work in the short term, you really have to look 10-20 years down the track.'

'The problem with nutrition is that the ethical issues associated with analytical studies of cause-effect between diet and disease make evaluation more observational... and this carries little weight with the evidence-based ideologues.'

I think the workforce has always been very critical of its own work, has reviewed its work practices and has done probably the best it can do given the sort of funding that it has had.'

There were also some strong opinions about the ineffectiveness of the workforce that reflect practice weaknesses:

'Useless... in fact I don't see how we can define how effective we have been because of poor evaluations... the lack of a logical coherent approach to defining problems and strategy development that aligns with that... we see a lot of reactive response put up in the name of public bealth nutrition.'

'I think we are failing to reach the vulnerable groups.'

There was a large range of factors suggested as limiting workforce effectiveness, mostly relating to resource inadequacies relative to the size of the problem, a lack of collaboration, co-ordination and existing service orientations that favour limited-reach clinical care:

'We are not doing very well because the size of the workforce is outweighed by the size of the problems.'

'We are really up against it because there are so many negative forces working against good nutrition.'

'We really haven't done much yet as we haven't given it a fair go...there is a lack of understanding of the potential of the workforce if it is adequately supported.'

'Our inability to work together has limited effectiveness, particularly in academia.'

'Service orientation is client-based rather than populationbased... So it makes it hard to be effective.'

\section{Discussion}

The use of a framework for inquiry using data from structured interviews in this study enabled the collation of information-rich data from a significant proportion of the 
small population of advanced-level public health nutrition practitioners in Australia. The quick onset of interview redundancy (i.e. few new themes introduced) experienced within groups and across academic and government-employed groups suggests that the range of responses achieved and the key themes identified were adequately captured. The potential for bias associated with the researcher's own views and interests in the topic and the proximity of the researcher to the interviewees (colleagues) have been countered by attention to and reporting of narrative presenting different views, emphasis on fair dealing and reflexivity as described by Mays and Pope $^{27}$. Nonetheless, readers should be aware of this potential bias.

Participant characteristics confirm the assumptions that interviewees sampled were advanced-level practitioners. The characteristics of interviewees typify recruitment criteria and career paths associated with senior-level employment in health departments and academia. The views expressed in this study reflect the attitudes and lived experience of the interviewees. As practitioners with dietetic training backgrounds fill most advanced-level positions in public health nutrition in the Australian health system, the views expressed reflect this experience and may differ from those of practitioners from nutrition training backgrounds other than dietetics.

Sample recruitment for this series of interviews did not extend beyond academics involved specifically in professional nutrition and dietetic preparation programmes such as dietetics, community nutrition and public health nutrition. It is recognised that a range of academics other than those included in this limited sample frame have an important role and make important contributions to public health nutrition efforts. Academic epidemiologists, health promoters and other public health academics are examples. All but one of the known government-level public health nutritionists was interviewed. Despite this good sample capture, the purpose of the qualitative method was to explore information-rich cases rather than obtain a representative sample.

Much of the international scholarship relating to public health nutrition workforce development ${ }^{16,17,22-25,28}$ has been centred on specific professional groups rather than a workforce that comprises different tiers with different contributions to the public health nutrition effort. The widespread recognition of the multidisciplinary nature of the public health nutrition workforce by advanced-level practitioners in Australia is consistent with the views of Rogers and Schlossman ${ }^{14}$, who advocate for cross-disciplinary application of competencies, and Pelletier $^{21}$, who argues the limitations of disciplinespecific knowledge. This recognition of the many professional groups who contribute to public health nutrition no doubt also reflects the reality of public health nutrition practice experience in Australia, where much of the implementation of nutrition interventions is delivered by non-specialists with or without specialist support.

The importance attributed to the leadership position of designated and specialist public health nutritionists, however, is obvious from this consultation. The mix of workforce development strategies required to develop practitioners with these specialist competencies is not able to be defined by this study and should be a focus of future research. Dietetics training appears to have been the favoured initial step for competency development amongst this Australian sample; however, this may reflect health system and professional structures that are not applicable in other countries. It also remains to be seen if dietetic training as a prerequisite to public health nutrition competency is the most efficient or effective workforce development pathway.

The large number of different competency units suggested reflects the breadth of skills, knowledge and applications required to address the often complicated problems encountered in public health nutrition practice. This also raises a question of whether competency considerations should focus on the competency requirements of the individual practitioner or the workforce/ multidisciplinary team. There appears to be agreement about the concept of core competencies (those that are applicable across jurisdictions and in different contexts) and that many of these are similar to those of generic public health practice as outlined in both the $\mathrm{USA}^{20}$ and Australia $^{19}$.

The competency expectations expressed by advancedlevel practitioners in Australia reflect findings from the public health nutrition-related competency literature in the USA ${ }^{14,24,25,29}$ and Europe ${ }^{22,23}$. Competency development scholarship in Australia has been limited to entrylevel dietetic practice ${ }^{30-32}$, which has limited applications to public health nutrition workforce development given the post-basic nature of competencies identified by interviewees in this study. Specific consideration of public health nutrition competency requirements in Australia has yet to be progressed beyond recognition of the need for such standards ${ }^{10}$. These qualitative data therefore provide a basis for further specific, competency-related research.

The main determinants identified that limit workforce effectiveness in Australia provide direction for workforce development strategy planning, including investments in workforce growth (particularly amongst the specialist workforce tier), better collaboration and systems for co-ordination.

\section{Conclusions}

Workforce capacity assessments presented in this study reflect the attitudes and experiences of interviewees that have been informed by experience and local knowledge. Given the lack of literature that directs assessment of workforce capacity and the limited workforce intelligence 
data in Australia, these views represent the best currently available intelligence relating to workforce capacity and illustrate the need for more research in this area.

\section{Acknowledgements}

The active co-operation and participation of the 41 advanced-level public health nutritionists in this study is acknowledged. The constructive comments of the anonymous reviewers are also appreciated.

\section{References}

1 Landman J. Training in Public Health Nutrition: symposium at the 17th International Congress of Nutrition, Vienna. Public Health Nutrition 2001; 4: 1301-2.

2 Hughes R, Somerset S. Definitions and conceptual frameworks for public health and community nutrition: a discussion paper. Australian Journal of Nutrition and Dietetics 1997; 54: 40-5.

3 Tapsell L. Letter to editor. Australian Journal of Nutrition and Dietetics 1997; 54: 153-4.

4 Woods J. Defining Public Health Nutrition and Community Nutrition. Melbourne: National Specialty Program in Public Health and Community Nutrition, 1996.

5 Niall M, O'Dea K. Viewpoint article: definitions and conceptual framework for public health and community nutrition - letter to editor. Australian Journal of Nutrition and Dietetics 1997; 54: 208.

6 Mackerras D. Viewpoint article: definitions and conceptual framework for public health and community nutrition letter to editor. Australian Journal of Nutrition and Dietetics 1998; 55: 37-8.

7 Hughes R. An omnibus survey of the Australian rural health dietetic workforce. Australian Journal of Nutrition and Dietetics 1998; 55: 163-9.

8 Hughes R, Somerset S. In reply to Ash et al. and Tapsell. Australian Journal of Nutrition and Dietetics 1997; 54: $154-5$.

9 Ash S, Capra S, Cumming F, Gibbons K, Roberts N, Tapsell L. Viewpoint article: definitions and conceptual framework for public health and community nutrition letter to editor. Australian Journal of Nutrition and Dietetics 1997; 54: 152-3.

10 Campbell K, Steele J, Woods J, Hughes R. Developing a Public Health Nutrition Workforce in Australia: Workforce Issues. Melbourne: National Specialty Program in Public Health and Community Nutrition, 1997.

11 Centers for Disease Control and Prevention/Agency for Toxic Substances and Disease Registry. Strategic Plan for Public Health Workforce Development. Toward a Life-long Learning System for Public Health Practitioners. Washington, DC: US Department of Health and Human Services, 2001.

12 Lichtveld M, Cioffi J, Baker E Jr, Bailey SB, Gebbie K, Henderson JV, et al. Partnership for front-line success: a call for a national action agenda on workforce development. Journal of Public Health Management and Practice 2001; 7(4): 1-7.

13 Strategic Intergovernmental Nutrition Alliance. Eat Well Australia: An Agenda for Action for Public Health Nutrition 2000-2010. Canberra: Department of Health and Aged Care, 2001.
14 Rogers B, Schlossman N. 'Public nutrition': the need for cross-disciplinary breadth in the education of applied nutrition professionals. Food and Nutrition Bulletin 1997; 18: $120-33$.

15 Public Health Association of Australia, Inc. (PHAA) Workforce Issues for Public Health: The Report of the Public Health Workforce Study 1990. Canberra: PHAA, 1990.

16 Adamson A, Cowburn G. Community nutrition and dietetics: a survey of nutrition group members in 1995. Journal of Human Nutrition and Dietetics 1996; 9: 339-48.

17 Haughton B, Story M, Keir B. Profile of public health nutrition personnel: challenges for population/systemfocused roles and state-level monitoring. Journal of the American Dietetic Association 1998; 98: 664-70.

18 Gatchell S, Woolcott D. A demographic profile of Canadian public health nutritionists. Journal of the Canadian Dietetic Association 1992; 53: 30-4.

19 National Public Health Partnership (NPHP). Public Health Practice in Australia Today - Core Functions. Melbourne: NPHP, 2001.

20 US Department of Health and Human Services (DHHS). The Essential Public Health Services Work Group of the Core Public Health Functions Steering Committee. Washington, DC: DHHS, 1995.

21 Pelletier D. Advanced training in food and nutrition: disciplinary, interdisciplinary, and problem orientated approaches. Food and Nutrition Bulletin 1997; 18: 134-45.

22 Yngve A, Sjostrom M, Warm D, Margetts B, Rodrigo CP, Nissinen A. Effective promotion of healthy nutrition and physical activity in Europe requires skilled and competent people; European Master's Programme in Public Health Nutrition. Public Health Nutrition 1999; 2: 449-52.

23 Landman J, Buttriss J, Margetts B. Curriculum design for professional development in public health nutrition in Britain. Public Health Nutrition 1998; 1: 69-74.

24 Hess A, Haughton B. Continuing education needs for public health nutritionists. Journal of the American Dietetic Association 1996; 96: 716-8.

25 Dodds J, Polhamus B. Self-perceived competence in advanced public health nutritionists in the United States. Journal of the American Dietetic Association 1999; 99: 808-12.

26 Kennedy V, Moore F. A systems approach to public health workforce development. Journal of Public Health Management and Practice 2001; 7: 17-22.

27 Mays N, Pope C. Qualitative research in health care. Assessing quality in qualitative research. British Medical Journal 2000; 320: 50-2.

28 Johnson D, Eaton D, Wahl P, Gleason C. Public health nutrition practice in the United States. Journal of the American Dietetic Association 2001; 101: 529-34.

29 Olmstead-Schafer M, Story M, Haughton B. Future training needs in public health nutrition: results of a national delphi survey. Journal of the American Dietetic Association 1996; 96: $282-3$.

30 Ash S, Phillips S. What is dietetic competence? Competency standards, competence and competency explained. Australian Journal of Nutrition and Dietetics 2000; 57: 147-51.

31 Phillips S, Ash S, Tapsell L. Dietitians' views on the current competency standards for entry level dietitians. Australian Journal of Nutrition and Dietetics 2000; 57: 190-7.

32 Phillips S, Ash S, Tapsell L. Relevance of the competency standards to entry level dietetic practice. Australian Journal of Nutrition and Dietetics 2000; 57: 198-207. 